\title{
Research on the Curriculum Design and Practice of "Functional Analysis" in Local Normal University
}

\author{
Chen Yanfeng \\ College of mathematics, Tong hua Normal University \\ Jilin Province, China \\ Wenjianke2007@163.com
}

\author{
Duan Lifen \\ College of mathematics, Tong hua Normal University line \\ Jilin Province, China \\ Yfchenth@126.com
}

\begin{abstract}
Functional analysis is a new branch in modern mathematics. It is integrated with the analysis of many problems in mathematics. It is a new method of comprehensive application for algebra and geometry. This paper analyzes the development of Functional Analysis course in Local Normal University, and puts forward some ideas on the reform of functional analysis in the teaching of Functional Analysis in the aspects of teaching skills, optimizing the contents of teaching materials, paying attention to the teaching method of curriculum, strengthening the ability of the students, strengthening the teaching reform of the course.
\end{abstract}

Keywords-functional analysis; local normal university; curriculum design; Mathematics Specialty; teachers; teaching

\section{INTRODUCTION}

Mathematics specialty developing course is often more abstract, the most typical course is functional analysis. Functional analysis is an important course in the Mathematics Department of China and foreign countries. It has been hailed as the twentieth Century calculus by the scientific community. It is an analysis of the functional and operator theory in infinite dimensional linear space[1]. The content includes three parts: the first is the space theory, including the space, Banach space, Hilbert space, the second is the operator theory, linear operator theory, linear functional theory; the third is the application of the disciplines, three parts are the organic combination. At present, functional analysis has become a subject of rich content and wide application. Some of the main results of functional analysis are the continuation, development, deepening and extension of classical analysis. The functional analysis of the undergraduate students learning is the basis and core of the content, it has a wide and deep penetration to the mathematics and applied mathematics major in other courses and other subjects[2]. For example, in the modern mathematical physics equation, a variety of functional space is a special Bametl space and Hilbert space, etc.. Differences in the past mathematics called three foundations (mathematical analysis, advanced algebra, analytic geometry), people often think of functional analysis, abstract algebra, topology, also

The teaching reform of Jilin Province higher education in 2014 "Curriculum Design and Practice of Functional Analysis in Local Normal University"; Teaching reform of higher education in Tonghua Normal University"Research on the Innovation of Talents Training Mode Best wishes, ased on the Diversified mathematics Curriculum Reform” (2015). known as the new foundations.

Due to some objective reasons that college teachers and students feel functional analysis course is hard to teach and learn, because, functional analysis whether the issues specific analysis and abstract to a more purely algebraic and topological structure form. It combines algebraic and geometric means to deal with the problems. Because of the functional analysis of the pure form of algebra and topological structure, it leads to its abstract nature. Most of the students in Local Normal University consider functional analysis to be difficult to learn, and then think that learning functional analysis is not helpful to the future[3].

\section{ANALYSIS OF THE CURRENT SITUATION OF FUNCTIONAL ANALYSIS}

The functional analysis teachers of local universities should grasp the students' level of mathematical ability and mathematics literacy; optimize the teaching content and structure of functional analysis course. At present, the functional analysis textbooks used by colleges and universities are written by 211 university teachers. However, the mathematics quality and abstract thinking ability of the students in local normal universities is not as good as the 211 university students, and the total time of the functional analysis of the local normal university is very little. This means that the local normal university teachers can not teach the students all the teaching contents of the functional analysis, the local universities teachers should be based on the characteristics of the students and the teaching time limit and so on. In the organization of lectures, more knowledge of the basic concepts and basic theorems of functional analysis should be considered. During the teaching of functional analysis, the author takes the form of a special subject (as shown in Figure 1). The first topic is metric spaces and normed linear space (12 hours); the second topic is bounded linear operator and continuous linear functional ( 8 hours); the third topic is inner spaces and Hilbert space (12 hours); the fourth topic is the basic theorem in Banach Spaces (18 hours). This arrangement functional analysis of teaching content, so that students can have a better understanding of the functional analysis of the main basic 
knowledge and important results, but also in the teaching hours to complete the relevant teaching tasks[4-8].

\begin{tabular}{|c|c|c|c|c|c|c|}
\hline course & lecture & experiment & training & exercises & coarh & subtotal \\
\hline $\begin{array}{l}\text { metric spaces and normed } \\
\text { linear space }\end{array}$ & 8 & & & 4 & & 12 \\
\hline $\begin{array}{l}\text { bounded linear operator and } \\
\text { continuous linear functional }\end{array}$ & 6 & & & 2 & & 8 \\
\hline inner spaces and Hilbert space & 8 & & & 4 & & 12 \\
\hline $\begin{array}{l}\text { the basic theorem in Banach } \\
\text { Spaces }\end{array}$ & 12 & & & 4 & 2 & 18 \\
\hline total & 34 & & & 14 & 2 & 50 \\
\hline
\end{tabular}

Fig.1. Functional analysis course teaching link and class hour arrangement

Although local universities are the teaching oriented universities, in a certain extent, the voice of the teachers engaged in scientific research is not so high, but this does not mean that the local universities teachers have to understand the latest research trends. On the contrary, as a professional teacher, especially in professional development, teachers should be aware of the relevant research trends in the course. In the case of functional analysis, the teacher should take the initiative to understand the latest research results related to the functional analysis of the teaching content, and try to integrate it into the functional analysis teaching. This is not only conducive to broaden students' horizons, for students in the eighth semester writing graduation thesis to lay a certain foundation, causing students learning interest in functional analysis, to cultivate students' mathematics creative thinking, and improve their mathematics study ability, to become a innovative thinking of basic education teachers foreshadowed. In fixed point theorem teaching, the author purpose enough principle to omit the proof of the theorem using saved time introduced the latest trends in the study of the fixed point theorem - G-measure space fixed point theorem, fuzzy normed space fixed point theorem[9]. In addition, the paper also introduces some of the results of the research on fixed point theorem, and provides the relevant information for students who are interested in doing research.

The main function of local universities is to train the people's teachers for basic education. Therefore, the professional teachers in these schools should not only master the professional knowledge, but also have a solid teaching theory and method, as the functional analysis of local normal universities should also be so.

\section{SOME REFLECTIONS ON THE REFORM OF FUNCTIONAL ANALYSIS}

\section{A. Master Teacher Education Skills}

Functional analysis teachers must not only master skills such as import, situation creation, writing on the blackboard design, lectures, questions, guidance and the end of the class, but also show ability to utilize these teaching skills in teaching. The author's school mathematics and applied mathematics major is the teacher education kind of profession, most students will take the platform after a year, become the people's teacher. For the fourth class students, master the textbook knowledge is important, but they also want to learn to deal with the skills of teaching materials. Therefore, the teachers in the teaching process can arouse students to learn functional analysis of the initiative. Functional analysis of universities students is a relatively abstract curriculum, as if high school students think middle school mathematics abstract difficult to learn. In this way, the methods, techniques of functional analysis teaching content for the functional analysis course in local universities, have a very strong reference to them in the future.

\section{B. Understand the Latest Research Results of Teaching}

In local universities, the teachers should be aware of the latest research results, and as far as possible to the latest teaching ideas, teaching mode and so on to the functional analysis of the classroom teaching. Since 2014, the research and the introduction of the teaching mode of the flipped classroom and the micro class is very fashionable, and the author also tries to introduce the teaching mode to the teaching of functional analysis. On the one hand, it can make the students master the professional knowledge better and faster, improve the teaching effect. On the other hand, it gives the students the latest teaching ideas and the impact of the teaching mode, so as to update the students' teaching idea[10].

\section{Optimize the Contents of Teaching Materials}

With the implementation of the Ministry of education, the teaching and research activities are carried out in Colleges and universities. Some key university organizations have rich experience in teaching and education experts have written many sets of other functional analysis materials. These materials have their own characteristics. East China Normal University Chen Qixiang who written "real function and functional analysis" that introduced functional analysis of the core content, including space, Banach spaces and Hilbert space, metric space and the basic concept of linear operators and linear functional important theorems. For the spectral theory of operators, the fully continuous self adjoint operator is introduced. The book focuses on the unity of the scientific system of normal and functional analysis, the functional analysis of the widely used in normal colleges and universities Wuhan University Liu Peide compiled the "functional analysis" is one of the basic undergraduate textbook series for twenty-first Century. The book is considered for the past twenty years functional analysis of teaching research results, and in accordance with the training of outstanding talents in twenty-first Century to prepare the target. It is a teaching material that is suitable for the students to use in a better and more hours. In the selection of teaching materials, if regardless of the total number of students with basic and hours, blindly greedy pursuit of novelty and greed to perfection, it will cause such a situation: the first is to talk a lot of content, it is difficult for students to timely digest. Ultimately, functional analysis is the most basic concept to clear understand; the second is due to the textbooks for its readability, have its own theoretical knowledge system and closed, if restricted hours and knowledge span too much, will make some students felt difficult to accept, the formation of fragmentation sense. From the study psychology, this is not conducive to the students to 
accept the scientific system of functional analysis. The selected materials, blindly accommodate students based on poor practices should also be avoided. If the selection of teaching materials is too simple, it will cause a teacher back ten steps, the situation of the students back a hundred steps, is not conducive to the cultivation of talents.

After selecting the appropriate teaching material, we should optimize the teaching content and achieve the purpose of teaching. Optimizing teaching content is a process of analyzing and studying the teaching materials. In this process, what should be clear, which does not speak, what is the essence, what is the focus, what is the difficulty. Opened in our Mathematics Department 50 hours of normal undergraduate functional analysis teaching, for example, metric space, inner space, linear normed spaces, linear operators and linear functional concept and simple nature is based functional analysis and the related content should be fine; includes the norm, the concept of bounded linear operator and conjugate space must to be carefully clarifying its meaning; functional analysis of four theorems (functional extension theorem, open mapping theorem, the closed graph theorem, the inverse operator theorem) content including the idea proving should be carefully explained[11-13].

\section{Pay Attention to the Teaching Method of the Course}

The teaching process of basic mathematics is not a repeat process of human log understanding. It requires that the basic knowledge should be more firmly in the teaching plan. As the basis of functional analysis, the teaching of mathematical analysis, real variable function and so on is very important. Belong to the professional basic course of real variable function class in Mathematics in Chinese higher education system in the teaching plan, is a transitional course. The socalled commitment, it is a mathematical analysis of the course (the main part of the calculus), development, deepening and extension, on the contrary, it is functional analysis and other courses, so the teaching of real variable function, in terms of the premise to ensure that, in addition to the contents of the talk should be put on the commitment to do. That is to say in the teaching, to the real function of the main concepts and conclusions and the corresponding part of the calculus as closely as possible (as shown in Table 1).

TABLE 1. THE MAIN CONCEPTS AND CONCLUSIONS IN REAL VARIABLE FUNCTION AND THE CORRESPONDING PART OF THE CLOSE RELATION OF THE CALCULUS

\begin{tabular}{|c|c|}
\hline $\begin{array}{c}\text { main concepts in real variable } \\
\text { function }\end{array}$ & $\begin{array}{c}\text { the corresponding part of the } \\
\text { calculus. }\end{array}$ \\
\hline measure & knowledge of collective theory \\
\hline Lebesgue integral & $\begin{array}{c}\text { definition and properties of } \\
\text { definite integrals }\end{array}$ \\
\hline $\begin{array}{c}\text { metric space and its } \\
\text { completeness }\end{array}$ & $\begin{array}{c}\text { completeness of real numbers } \\
\text { properties }\end{array}$ \\
\hline $\begin{array}{c}\text { and space and its basic } \\
\text { profinition and properties of } \\
\text { number series }\end{array}$ \\
\hline space and its dual space & Fourier series \\
\hline $\begin{array}{c}\text { concepts and fixed point } \\
\text { theorems for fixed points }\end{array}$ & application of differential \\
\hline
\end{tabular}

As a result, some basic concepts of real variable functions are to be learned, and to be able to start the next. But two aspects, the teaching and learning in mathematics is a variety of teaching activities through the teachers, so that students get the initiative of learning mathematics, we must pay attention to the teaching method reform, handle the relationship between teachers and students. A university teacher, should be able to flexibly use the teaching style, sample, construction three teaching methods, using their own in the long-term teaching and scientific research and practice in the teaching of mathematics ideas and research methods, through the specific teaching content, to teach students to teach, guide them to analyze, put forward problems, to study, to innovate. In addition, students learning and understanding the mathematical process is not only a process of cognition, and this is also the will of the temper, emotional edify and other non-intellectual and moral cultivation. So the teachers should also pay attention to the mathematics of humanism spirit in the cultivation of students' rational spirit and aesthetic sentiment; equally with the students discuss issues, enthusiastically encourage them to ask as many questions as bold to express different opinions; be careful of the drip and innovation consciousness of students and cultivate their innovative spirit; the teacher's words and deeds to students, especially a great impact on the lower grade student just entered the university soon. As a basic course teachers should try to make students good teachers and helpful friends. It should also be emphasized that the relationship between the teaching practice and the basic training of mathematics and the application of mathematics[14].

\section{E. Strengthening the Cultivation of Learning Ability}

One of the ultimate goal of teaching is to cultivate students' thinking ability, to compare the knowledge in the process of teaching and learning, so that the new knowledge and the relevant knowledge of the original knowledge are interrelated, so as to achieve the understanding of these issues and conclusions of the memory more profound. Learning functional analysis conception also pays attention to the concept of mathematical analysis, real variable function. In order to encourage students to ask questions, as follows:

- Require the students to ask questions, not to ask the teacher questions is a waste of teaching resources.

- Do not understand the question must be asked, and to timely ask.

- Do not think that they do not understand the question, if students are not to ask questions, teachers can not think students are fully understood, then to ask questions.

\section{F. Penetrating Mathematics Method}

Permeability is combined with the teaching contents, repeatedly, and step by step, to enable students to implement the process from quantitative change to qualitative change in imperceptible in. Mathematics method is the basic point of view; it is the nature of mathematics knowledge and mathematics recognizition. The mathematical method is to guide study and discuss the development law of mathematics and the science of discovery, invention and innovation. Teachers should pay more attention to the teaching of mathematical ideas and methods to cultivate students' mathematical thinking[15].

The teaching of functional analysis in many colleges and universities is often the same as other courses, which is always 
the teacher's teaching, students listen to lectures, take notes, class students read notes and digest the contents of the study, and then do exercises to be applied. On the surface, this process can make every student get a lot of knowledge in a short time, and improve the teaching efficiency. But from the point of view nature, the teaching and learning process, each students completely as passive receivers, ignored the students learning initiative and autonomy, is not conducive to the cultivation of students' self-learning ability, but in modern society, the knowledge update faster and faster, self-learning ability is increasingly important. Therefore, it should be combined with teaching content, improve teaching mode, and strive to cultivate students' self-learning ability. After each lesson, you can set up some appropriate questions for the next section, and guide students to preview the contents of the study. This is to accelerate the pace of teaching, highlighting the focus and difficulty of teaching is very good. In addition, students in the preview will be found not to understand the problem; so as to bring the problem into the classroom, listening to the lessons will be more targeted.

\section{G. Strengthen Exercise Guidance}

In the middle school mathematics teaching, every class is used for a few minutes to review some of the old lessons about the new class. In the classroom teaching in University, is directly into the new curriculum, seldom review the old lessons. For the basis of poor students, schoolwork burden is heavy is the actual situation, we can learn from middle school mathematics teaching experience, each class is taking a few minutes time is briefly reviewed and the new lesson about some old course content, to consolidate the knowledge and setting curriculum content expansion.

In the teaching of functional analysis, it is not only reflected in the abstract and difficult to understand, but also difficult to understand the theoretical method, difficult to use, difficult operation. A lot of students are often able to understand the content of the classroom, but facing of problems are always helpless. For a long time, this will cause the students not like to learn this course, it is difficult to learn the negative psychological understanding of the course. Therefore, it is very important to select the appropriate typical problems, to solve the difficult problems and to strengthen the students' learning confidence[16]

\section{H. Reform Test Method}

The main teaching content and method needs to reform, the purpose is to improve the quality of the course, but its effective implementation should be actively cooperate to achieve the desired results by the students. In this way, the study of the students must have a certain constraint and incentive mechanism. In addition to grasping the limited classroom teaching process, examination is a powerful tool for teachers to mobilize students to study. Since the reform of this course requires students to pay a certain amount of time and energy to study and explore in the outside class, in order to guarantee the validity of this process, we must reform the traditional test mode. Therefore, the test can be divided into four parts (as shown in Table 2): normal operations, accounting for $10 \%$; classroom discussion, accounting for $10 \%$; extracurricular research papers, accounting for $30 \%$; final exam papers, accounting for $50 \%$. After several years of practice, this model is not only welcomed by the students, but also effectively improve the initiative to mobilize the students to participate in class, actively participate in class discussions and carry out extra-curricular activities.

TABLE 2. FUNCTIONAL ANALYSIS COURSE TEST SCORE STANDARD

\begin{tabular}{|c|c|}
\hline scoring criteria & proportion \\
\hline normal operation & 10 \\
\hline classroom discussion & 10 \\
\hline extracurricular research papers & 30 \\
\hline final exam papers & 50 \\
\hline
\end{tabular}

To sum up, I think as a local normal universities functional analysis teachers must set up the ideas of teaching and academic, as do research for teaching, grasp the spirit of functional analysis teaching content, grasp the functional analysis latest research trends, research on teacher education methods and skills, understand the new teaching methods and teaching philosophy. Only in this way, the professional teachers in the Local Higher Normal University can set up a role model for the future people and earn the respect of the students.

In the course of functional analysis, improving teaching methods, improving the teaching effect of functional analysis, selection of teaching materials, optimizing the content is the premise, taking good teaching method, improving the efficiency of classroom teaching is the key.

\section{REFERENCES}

[1] Q.X. Cheng, D.Y. Zhang, G.Q. Wei, et al,Foundation of Real Variable Function and Functional Analysis (Third Edition) ,Beijing: Higher Education Press, 2010.

[2] F. Gu, S. Zhou, "Coupled common fixed point theorems for a pair of commuting mappings in partially ordered G-metric spaces,"Fixed Point Theory and Applications, vol.64,2015.

[3] J. Zhu, Y. Wang, C. Zhu, "Fixed point theorems for contractions in fuzzy normed spaces and intuitionistic fuzzy normed spaces," Fixed Point Theory and Applications, vol.79,2013.

[4] B.D. Chen, "Some suggestions on Teaching of functional analysis,"Journal of Xinjiang Normal University, April 2006.

[5] Fixed point theory and applications. http://www.fixedpoint heoryandapplications.com.

[6] G.X. Wang, Z.M. Zhou, S.M Zhu, et al,Ordinary Differential Equations (Third Edition) ,Beijing: Higher Education Press, 2007.

[7] Y. Wang, Y.L. Zhang, B.H. Zhang, "Research on classroom teaching mode," Journal of Distance Education, vol.4,pp. 46-51,April 2012.

[8] T.H. Hu, "Micro lesson: a new trend in the development of regional education information resources ," Audio Visual Education Research, vol.10,pp. 61-65,2011.

[9] X.A.Xu, "the explore of functional analysis teaching method,"Advanced Mathematics Research, vol.11,January 2008.

[10] D. Ru,Functional Analysis,Beijing: Engineering Industry Press, 2004

[11] G.Q. Zhang, Y.Q. Lin,Flac of Functional Analysis,Beijing: Peking University Press, 2000 .

[12] L.H. Dong. "Further research on Teaching of Functiona analysis,"Studies in College Mathematics, vol.8,pp. 53-55,March 2010.

[13] Z.R. Guan, "A functional analysis teaching methods in the course of intravenous drip experience," Journal of Ningxia University (natural science edition), vol.4,2015

[14] J.Wang, "Functional analysis teaching reform in the course of discussion and research". China Education Innovation Herald, vol.4,2011. 
[15] X.D. Li,H. Akca,X.L. Fu, "Uniform stability of impulsive infinite delay differential equations with applications to systems with integral impulsive conditions,"Applied Mathematics and Computation,2013.

[16] X.D. Li,M. Bohner, "An impulsive delay differential inequality and applications,"Computers and Mathematics with Applications, vol.6,2012. 